\title{
THE SYNTHESIS OF HEME AND GLOBIN IN THE MATURING HUMAN ERYTHROID CELL*
}

\author{
By DAVID G. NATHAN, SERGIO PIOMELLI AND FRANK H. GARDNER with the \\ TECH NICAL ASSISTANCE OF VIRGINIA B. LEMIRE
}

\author{
(From the Richard C. Curtis Hematology Laboratory, Peter Bent Brigham Hospital, and the \\ Department of Medicine, Harvard Medical School, Boston, Mass.)
}

(Submitted for publication December 9, 1960 ; accepted February 16, 1961)

This report describes observations on the rate of heme and globin synthesis within the maturation period of human marrow erythroid cells. Such studies have been designed to examine the hypothesis that heme and globin are synthesized with temporal independence during erythroid cell maturation and to establish the normal relationship of heme and globin synthesis. With such data it is hoped that further work may lead to a definition of some of the effects of certain hormones and drugs upon heme and globin synthesis and to closer examination of certain refractory anemias with particular emphasis on abnormalities of globin synthesis.

The rates of synthesis of heme and globin within the erythroid cell maturation period are defined in these studies by the daily incremental incorporation of glycine-2- $\mathrm{C}^{14}$ into peripheral blood hemin and globin and of $\mathrm{Fe}^{59}$ into red cells following intravenous administration of these precursors to four healthy male volunteers.

\section{MATERIALS AND METHODS}

I. Subjects. Four male subjects were selected for these studies. Two were patients in the general medical wards of the Peter Bent Brigham Hospital, and 2 were normal healthy members of Mary Knoll Fathers, Jamaica Plain, Mass. Subject 1 (C.A.) was a 58 year old male with evident right carotid insufficiency secondary to atherosclerosis. His peripheral blood values (hematocrit, hemoglobin, white blood cell count and differential) were normal. Subject 2 (A.C.) was a 55 year old male with moderately severe Parkinson's disease treated with Artane (trihexyphenidyl hydrochloride) during the course of the 5-day study. His peripheral blood values were normal. Subject 3 (F.T.) was a 33 year old male in excellent health, whose blood values were normal. Subject 4 (B.A.) was a 45 year old male with mild essential hypertension, whose blood values were normal.

* Supported by the United States Public Health Service Grant A-965 (C4), The Medical Foundation, Inc., The Milton Fund, and the Permanent Charity Fund.
The studies on Subjects 1 and 2 were performed in the hospital, while Subjects 3 and 4 were ambulatory. Diet and fluids were not regulated for any subject.

II. Procedure. Each subject received nearly simultaneous intravenous injections of $100 \mu \mathrm{c}$ of glycine-2-C $\mathrm{C}^{14}$ and $5 \mu \mathrm{c}$ of $\mathrm{Fe}^{59}$ as ferrous citrate; the latter was bound either to autologous plasma or to $15 \mathrm{ml}$ of group $\mathrm{AB}$ $\mathrm{Rh}$-positive fresh frozen plasma. Fifteen $\mathrm{ml}$ of heparinized blood was drawn daily for 7 days from each subject, except from Subject 2 whose blood was drawn for 5 days. Subjects 1 and 2 also received $1.5 \mathrm{~g}$ sodium benzoate by mouth 4 and 8 hours after the injection of isotopes, and daily thereafter. Hippuric acid was isolated from a 4-hour urine collection following each dose of sodium benzoate (1).

One $\mathrm{ml}$ of each blood sample was counted for $\mathrm{Fe}^{59}$ activity in a single-channel pulse-height analyzer with a sodium iodide thallium-activated crystal. Red cell iron uptake was calculated as previously described (1).

The remaining red cells were washed three times with saline, lysed with distilled water, shaken with $2 \mathrm{ml}$ of toluene and allowed to stand overnight at $5^{\circ} \mathrm{C}$. The lysate was centrifuged at $700 \mathrm{G}$ to separate lipid and stromal contents from hemoglobin. The hemoglobin solution derived during the first 2 days was dialyzed against running cold water for 12 hours to remsve traces of free glycine.

From the hemoglobin solution, hemin was separated by the technique of Labbé and Nishida (2), and globin was separated by a modification of the technique of Rossi Fanelli, Antonini and Caputo (3). The proiein was not dialyzed but simply washed copiously with the acetone- $\mathrm{HCl}$ mixture. $\mathrm{Fe}^{59}$ counts were not found in the protein, and the hemin preparation achieved constant specific radioactivity. The hemin, globin, and an aliquot of the hemoglobin solution were dried in vacuo and combusted to $\mathrm{BaCO}_{3}$ by a modification of the Van SlykeFolch technique (4). Thirty $\mathrm{ml}$ of the combustion fluid was added to 50 to $60 \mathrm{mg}$ of hemoglobin or globin and to 10 to $20 \mathrm{mg}$ of hemin. Carrier hemin was occasionally added to improve the yield of $\mathrm{BaCO}_{3}$. Combustion flasks were simmered on heating mantles for 20 minutes and $\mathrm{CO}_{2}$-free air swept through the flasks into $0.5 \mathrm{M} \mathrm{CO}_{2}$ free sodium hydroxide. Blank combustions were performed before each series of combustions. The $\mathrm{BaCO}_{3}$ samples were filtered, dried at $110^{\circ} \mathrm{C}$ for 12 hours and then weighed (weight $\mathrm{A}$ ). An aliquot of this total yield (weight B) was counted in a liquid scintil- 
lation spectrometer (5). The $\mathrm{BaCO}_{3}$ derived from heating of the combustion fluid alone (blank combustion) was determined (weight $\mathrm{C}$ ). The amount of $\mathrm{BaCO}_{3}$ in the counted sample which was utilized for the calculation of specific activity was considered equal to $\mathrm{B}-\mathrm{C}(\mathrm{B} / \mathrm{A}-\mathrm{C})$. In practice this correction for blank combustion was very small. The yields of $\mathrm{BaCO}_{3}$ were 85 to 100 per cent of theoretical yields from hemin, globin and hemoglobin combustion. No self-absorption was detected below $700 \mathrm{mg} \mathrm{BaCO}_{3}$ with this equipment. Hippuric acid was isolated, combusted, and counted to evaluate the rate of turnover of hepatic glycine.

From certain globin samples, glycine was isolated by the technique of Moore and Stein (6). This material (after addition of carrier glycine) was combusted to $\mathrm{BaCO}_{3}$ and similarly counted.

III. Calculations. The theoretical yields of $\mathrm{BaCO}_{3}$ from 100 per cent combustion of $1 \mathrm{mg}$ of hemoglobin, globin, and hemin are $8.3,8.4$, and $10.1 \mathrm{mg}$, respectively. Since repeated combustion of single samples produced satisfactory reproducibility of specific activity, the specific activity (counts per minute per milligram) of each $\mathrm{BaCO}_{3}$ sample was multiplied by the appropriate figure to derive the specific activity of hemoglobin, globin and hemin. The millimolar specific activity of glycine in globin (globin glycine) and in hemin (hemin glycine) was derived by dividing the globin value by 0.043 (milligrams of glycine in $1 \mathrm{mg}$ of globin) $(7,8)$ and multiplying by 75 (molecular weight of glycine), and by multiplying the hemin value by 652 (molecular weight of hemin) and dividing by 8 (number of millimoles of glycine in 1 mmole of hemin). The cumulative hemin and globin glycine specific activities were plotted for each day and a line drawn by inspection to connect the points. From these data and the iron uptake curve, the daily ratios of $\mathrm{Fe}^{59}$ specific activity and of hemin glycine specific activity to globin glycine specific activity were calculated and plotted. The daily increment of hemin and globin glycine specific activities was calculated from the cumulative hemin and globin curves and separately plotted. The theoretical hemoglobin specific activity was calculated frcm the addition of 4 per cent of the hemin specific activity and 96 per cent of the globin specific activity. This value was compared to the actual hemoglobin specific activity to evaluate the reproducibility of combustion technique and the thoroughness of the hemin and globin separations.

\section{RESULTS}

The data are summarized in Figures 1 and 2 . Each figure represents two studies and contains five sections for each study. The shapes of the iron incorporation curves would indicate minimal red cell maturation times of between 5 and 6 days.

SUBJECT ।

SUBJECT 2

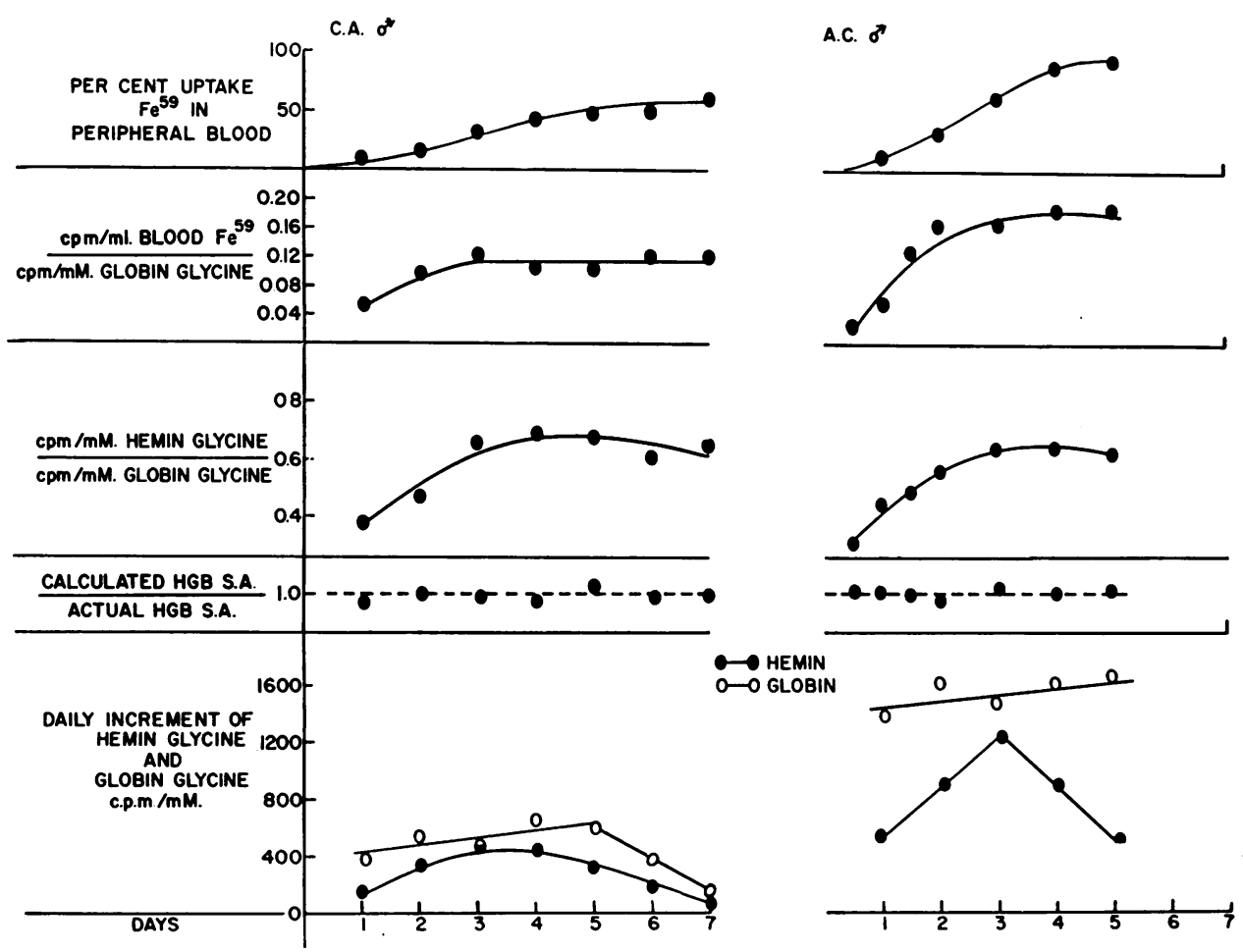

Fig. 1. Data from Subjects 1 and 2. The data are presented in five vertical sections for each subject (see text). 
SUBJECT 3

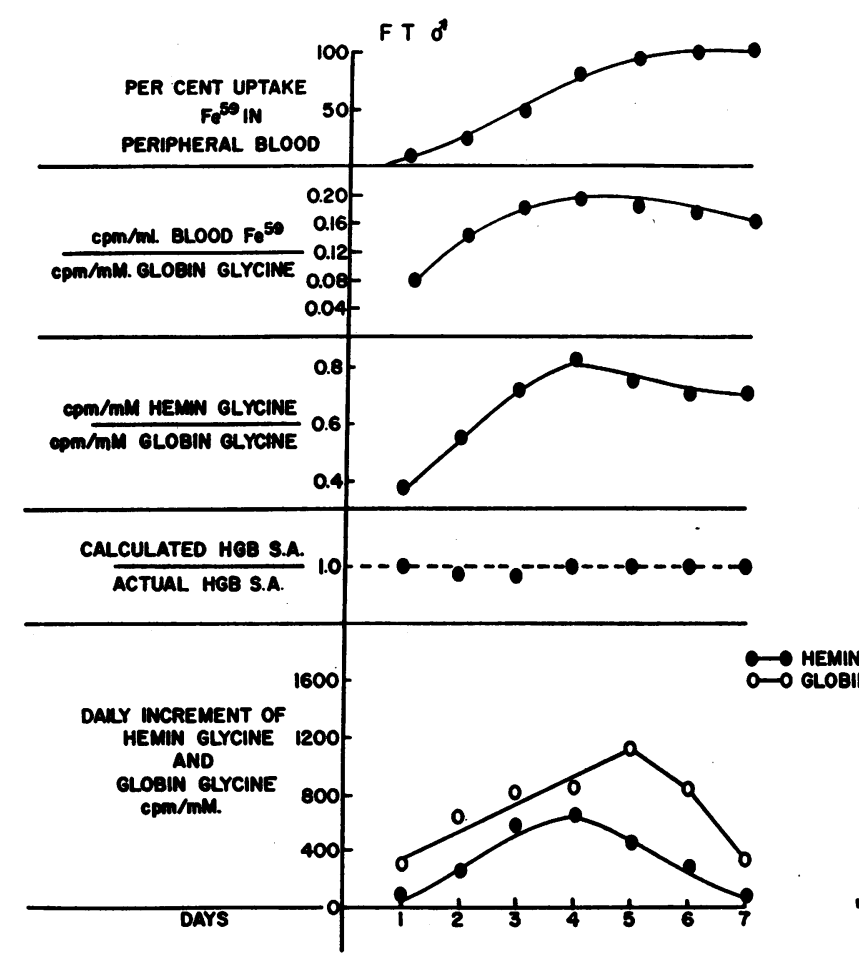

SUBJECT 4
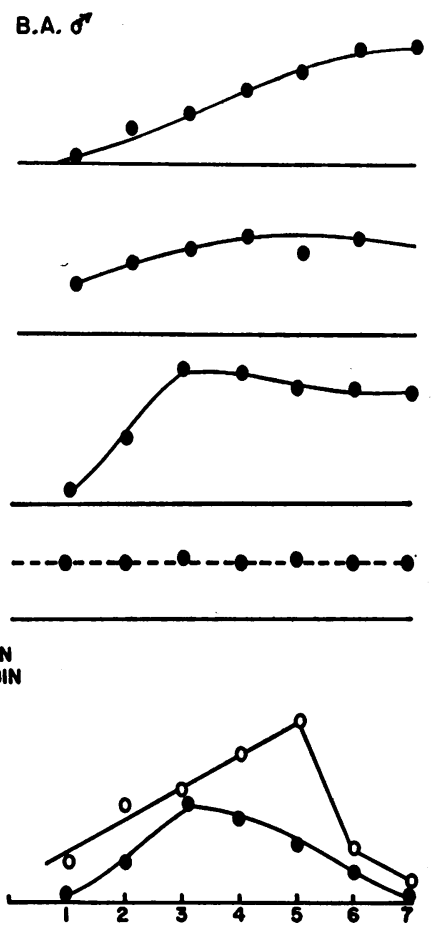

Fig. 2. Data from Subjects 3 and 4. The data are presented in five vertical sections for each subject (see text).

The curves representing the ratios of the $\mathrm{Fe}^{59}$ (cpm per ml blood) to the globin glycine (cpm per mmole) and the hemin glycine (cpm per mmole) to the globin glycine (cpm per mmole) are quite similar and indicate that the time required in vivo for synthesis of hemin from glycine and for insertion of iron into hemin are similar enough in normal males to be difficult to distinguish by these techniques.

The curve representing the ratio of hemin glycine to globin glycine would indicate that the initial cells emerging from the marrow following administration of glycine-2- $\mathrm{C}^{14}$ are more heavily labeled in the globin moiety than in the heme. As the days proceed, cells emerge with progressive increase of the ratio until a plateau is reached, which in each case is below that of unity.

Comparison of the hemoglobin specific activity calculated from the hemin and globin specific activities with the actual hemoglobin specific activities indicates that the data appear to be reproducible and reliable.

The glycine isolated from globin samples of the first, second and tenth day following glycine-2- $\mathrm{C}^{14}$ administration to Subject 1 had specific activities equal to 90,88 and 87 per cent of the calculated specific activities, respectively. This was probably due to some $\mathrm{C}^{14}$-labeling of the protein by amino acids which had been labeled by transfer of $\mathrm{C}^{14}$ from the glycine-2- $\mathrm{C}^{14}$.

The incremental hemin and globin glycine specific activity curves lend more information regarding the timing of hemin and globin synthesis in maturation than do the daily cumulative hemin glycine to globin glycine ratio curves. The former curves are, in effect, mirror images of the marrow relationships, since the cells which emerged on the first day were among the most mature cells in the marrow at the time of isotope administration. The cells appearing on the fifth day were probably among the most primitive cells of the erythroid series at the time of isotope administration. The cells appearing in the peripheral blood on the sixth and seventh days were not likely to have been in a line of progressive maturation at the time of the isotope introduction, but rather began 
their maturation when the marrow glycine was of relatively low specific activity following the introduction of the high specific activity "pulse."

The erythroid cells, which were primitive at the time of the radioactive glycine "pulse," appeared in the peripheral blood on the fifth day and had incorporated glycine into globin actively. There is then progressive diminution of this uptake as the cell matures. The changes in hemin specific activity are qualitatively different with a rather bell-shaped curve of glycine uptake and a peak at 3 to 4 days. The curves are not identical, but are very similar in each case. The globin curves decline more steeply in Subjects 3 and 4 than in Subjects 1 and 2 . The daily globin increment is greater than the hemin increment but approximates the hemin increment at the hemin peak. There is variability in the approximation from subject to subject. These data suggest that hemin and globin are synthesized in variable proportions depending on the stage of cell maturation.

Figure 3 portrays a representative hippuric acid specific activity curve following the administration of glycine-2-C $\mathrm{C}^{14}$ to Subject 1 . Of note is the fast clearance of the body burden of radioactive glycine, implying a rapid turnover of glycine in the liver. Hippuric acid specific activity extrapolated to zero time does not fairly represent the peak specific activity of liver glycine, since the rate of decline within the first hour or even the first 4 hours is not measured. The data of $\mathrm{Ne}-$ mer, Wise, Washington and Elwyn (9) regarding the rate of decline of the specific activity of hepatic L-serine following the administration of
L-serine-3- $\mathrm{C}^{14}$ to rats show that the most abrupt change is measured within the first several minutes after injection.

\section{DISCUSSION}

Numerous studies have been performed to elucidate the peak synthetic rates of heme and globin during the maturation of the erythroid cell. The early data of Thorell (10) and the experiments of Muir, Neuberger and Perrone (11), Altman and associates (12) and Kassenaar, Morell and London (13), some of whom have used quite different approaches to the problem, lend credence to the thesis that a temporal dissociation of the synthetic rates of these compounds exists. However, species differences are noted, and the in vitro studies of Kruh and Borsook (14), and of Morell, Savoie and London (15), do not support this impression. There is little information regarding human physiology in this regard, although the recent work in humans of Bannerman, Grinstein, Moore and Varva $(16,17)$ would suggest a dissociated mechanism.

The technical approach to the problem adopted in this report involves the measurement of the hemin and globin specific activity of the peripheral blood following the introduction of a "pulse" of glycine-2- $\mathrm{C}^{14}$ and $\mathrm{Fe}^{59}$. The increment of carbon specific activity in the two compounds is thought to represent the uptake of the isotope into the products in each of the maturing erythroid cells of marrow. These cells mature and emerge from the marrow as reticulocytes with final heme and globin specific activities that are direct functions

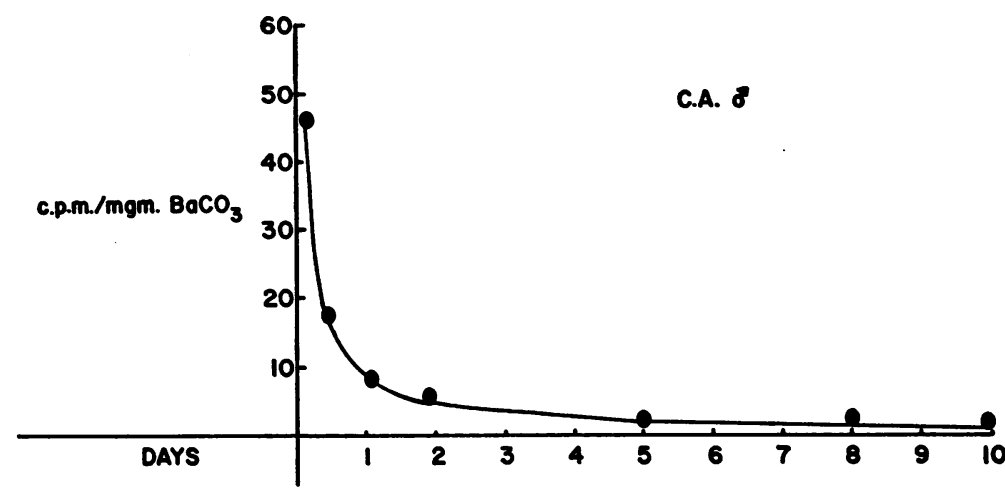

Fig. 3. URINARY HIPPURIC ACID SPECIFIC ACTIVITY FOLLOWING INTRAvenous glycine-2-C ${ }^{14}$ administration to Subject 1 . The results are expressed as the specific activity of $\mathrm{BaCO}_{3}$. 
of their uptake of the "pulse" of precursor and their previous or subsequent synthesis of heme and globin from nonradioactive precursor glycine.

The ranges of synthetic rates of each compound as a function of maturation may then be assessed from the incremental curves with the following assumptions. 1) The intracellular precursor pools of glycine for heme and globin are of equal specific activity in each cell. 2) The radioactivity of the glycine in the marrow rapidly achieves a high concentration and falls swiftly to low levels so that persistent labeling of the cells not exposed to the high "pulse" contributes very little to the incremental curve. 3) No appreciable amounts of intermediate compounds, which exist between glycine and the products under scrutiny, are present in concentrations capable of diluting the precursor for one compound in excess of the other. 4) There must be no appreciable turnover or reutilization of parts of one product in excess of the other. 5) Net synthesis of the products must be shown to occur. These stipulations have recently been carefully reviewed by Russell (18).

Some, but not all, of the above assumptions have been evaluated during these experiments. 1) No information regarding possible separate pools of glycine for heme and globin synthesis in human erythroid cells is available. Recent evidence has been presented (19) to indicate that different human tissues maintain varying glycine specific activities following glycine-2- $\mathrm{C}^{14}$ administration so that the concept of a single homogeneous body pool of glycine is no longer acceptable. The recent publications of Rabinovitz and Olson (20) and of Kipnis and Reiss (21) indicate a linear uptake of certain radioactive amino acids into protein in vitro as though little mixing of the amino acids in an intracellular pool had taken place. 2) The urinary hippuric acid specific activity curve indicates that the high pulse of radioactivity, at least in the liver, is short. The first value is taken 4 hours after the administration of glycine and greatly underestimates the actual peak specific activity of glycine which is achieved (9). 3) The problem of intermediate compounds has been approached by assuming that such intermediates are more likely to be detected along the heme rather than the globin pathway. That this assumption may not be valid is best shown by the complex kinețics of reticulocyte protein syn- thesis described by Rabinovitz and Olson (20). Attempts to bypass the heme intermediates by the use of radioiron showed that the rates of iron and glycine incorporation were quite similar by this technique. However, the work of Allen and Jandl (22) would indicate that this may be fortuitous, since these workers have demonstrated complex kinetics of iron incorporation into heme, including delay of passage of iron through the stroma which causes a lag phase in the appearance of iron in the heme. 4) Turnover and re-utilization of heme and globin within the marrow has not been established. The well known early stercobilin peak (23) is associated with erythropoiesis, but whether it is due to medullary heme turnover, erythroid cell death (24) or destruction of excess peripheral reticulocytes, is not established. Definite information on globin turnover is lacking. If medullary erythroid cell death is responsible for the early stercobilin peak, heme and globin would be expected to be catabolized or re-utilized at equal rates within the marrow. 5) Net synthesis of heme and globin by the marrow is obvious, but measurements of peripheral blood specific activity do not take into account the complex processes of cell division (25-27) which accompany maturation throughout the marrow. The heme and globin incremental curves reflect not only the synthetic rates of the compounds but also the number of cells of a given stage of maturation present in the marrow at the time of isotope administration (24).

The above considerations prevent rigid interpretation of these data. The results do suggest, however, that globin and heme are not synthesized at equal rates throughout maturation. It appears that the globin synthetic rate is maximal very early in maturation and that the rate steadly declines during maturation. Heme synthesis appears to be maximal during the mid-portion of maturation and is less intense during the early and late phases.

Some confirmation of these interpretations is available from recent radioautographic studies of human marrow in vitro. Gavosto, Maraini and Pileri (28) have shown that the human proerythroblast takes up approximately 15 times the amount of tritiated leucine as does the polychrumatophilic erythroblast. Since the bulk of proerythroblasts divide several times before maturation and emergence from the marrow, their final globin specific activities might be expected to be 
two or three times that of the cells which emerge 1 day after the "pulse" of glycine-2-C $\mathrm{C}^{14}$ is given. This type of relationship is observed in the incremental curves. Unfortunately, $\mathrm{Fe}^{59}$ radioautographs do not reflect heme synthesis and cannot be used in comparison, since so much of the iron in the early cells appears to be present as ferritin and not as heme (29).

The finding of temporal independence of heme and globin synthesis in human red cell maturation presages the detection of lesions of production of one or the other compound (30). Perhaps the most common of lesions, iron deficiency, may have as its counterpart a refractory anemia due to deficient production of globin. Thalassemia may be a special form of such a syndrome.

The daily and incremental curves not only suggest independence of heme and globin synthesis but also imply that reticulocytes may emerge from the marrow containing concentrations of globin above those consistent with their hemoglobin concentrations, since the cells which emerge on the first day maintain a higher globin than heme specific activity. This state may contribute to the macrocytosis, hypochromia and polychromatophilia of reticulocytes. Reticulocyte maturation may include a process of extirpation of excess globin. Further data are required to evaluate this hypothesis.

\section{SUM MARY}

1. An in riz'o method of measuring the timing in red cell maturation of heme and globin synthesis has been described.

2. The data in four normal patients are presented.

3. The data indicate that globin synthesis commences at a very primitive stage of maturation and continues throughout maturation with a linear decline in synthetic rate. Heme synthesis appears to be most active at a more developed stage of maturation, and the bulk of heme synthesis is confined to a more narrow span of the maturation time.

4. The rates of incorporation of iron and glycine into heme appear nearly equal in vivo.

5. The difficulties in interpretation of these data are discussed.

\section{ACKNOWLEDGMENTS}

The authors wish to thank Dr. David Elwyn and Dr. David Gitlin for their assistance with chromatographic techniques and Dr. Rudi Schmid for helpful suggestions and manuscript review.

\section{REFERENCES}

1. Nathan, D. G., and Berlin, N. I. Studies of the production and life span of erythrocytes in myeloid metaplasia. Blood 1959, 14, 668.

2. Labbé, R. F., and Nishida, G. A new method of hemin isolation. Biochim. biophys. Acta 1957, 26, 437.

3. Rossi Fanelli, A., Antonini, E., and Caputo, A. Studies on the structure of hemoglobin. I. Physiocochemical properties of human globin. Biochim. biophys. Acta 1958, 30, 608.

4. Van Slyke, D. D., Plazin, J., and Weisiger, J. R. Reagents for the Van Slyke-Folch wet carbon combustion. J. biol. Chem. 1951, 191, 299.

5. Nathan, D. G., Davidson, J. D., Waggoner, J. G., and Berlin, N. I. The counting of barium carbonate in a liquid scintillation spectrometer. J. Lab. clin. Med. 1958, 52, 915.

6. Moore, S., and Stein, W. H. Chromatography of amino acids on sulfonated polystyrene resins. J. biol. Chem. 1951, 192, 663.

7. Hill, R. J., and Craig, L. C. Countercurrent distribution studies with adult human hemoglobin. J. Amer. chem. Soc. 1959, 81, 2272.

8. Stein, W. H., Kunkel, H. G., Cole, R. D., Spackman, D. H., and Moore, S. Observations on the amino acid composition of human hemoglobins. Biochim. biophys. Acta 1957, 24, 640.

9. Nemer, M. J., Wise, E. M., Jr., Washington, F. M., and Elwyn, D. The rate of turnover of serine and phosphoserine in rat liver. J. biol. Chem. 1960, 235, 2063.

10. Thorell, B. Cellular formation of intermediates during haemoglobin synthesis in Ciba Found. Symp. on Porphyrin Biosynthesis and Metabolism, G. E. W. Wolstenholme and E. C. P. Millar, Eds. Boston, Little, Brown, 1955, p. 174.

11. Muir, H. M., Neuberger, A., and Perrone, J. C. Further isotopic studies on haemoglobin formation in the rat and rabbit. Biochem. J. 1952, 52, 87.

12. Altman, K. I., Casarett, G. W., Masters, R. E., Noonan, T. R., and Salomon, K. Hemoglobin synthesis from glycine labeled with radioactive carbon in its $\alpha$-carbon atom. J. biol. Chem. 1948, 176, 319.

13. Kassenaar, A., Morell, H., and London, I. M. The incorporation of glycine into globin and the synthesis of heme in vitro in duck erythrocytes. J. biol. Chem. 1957, 229, 423. 
14. Kruh, J., and Borsook, H. Hemoglobin synthesis in rabbit reticulocytes in vitro. J. biol. Chem. 1956, 220, 905.

15. Morell, H., Savoie, J. C., and London, I. M. The biosynthesis of heme and the incorporation of glycine into globin in rabbit bone marrow in vitro. J. biol. Chem. 1958, 233, 923.

16. Bannerman, R. M., Grinstein, M., and Moore, C. V. Haemoglobin synthesis in thalassaemia; in vitro studies. Brit. J. Haemat. 1959, 5, 102.

17. Grinstein, M., Bannerman, R. M., Varva, J. D., and Moore, C. V. Hemoglobin metabolism in thalassemia ; in vivo studies. Amer. J. Med. 1960, 29, 18.

18. Russell, J. A. The use of isotopic tracers in estimating rates of metabolic reactions. Perspec. Biol. Med. 1958, 1, 138.

19. Schapira, G., Dreyfus, J. C., Kruh, J., Labie, D., and Padieu, P. Absence of a single metabolic pool of free tissue glycine in Proceedings of the Second United Nations International Conference on the Peaceful Uses of Atomic Energy. Geneva, United Nations, 1958, vol 25, part 2, p. 21.

20. Rabinovitz, M., and Olson, M. E. Protein synthesis by rabbit reticulocytes. I. Kinetics of amino acid incorporation in vitro into protein fractions of intact cells. J. biol. Chem. 1959, 234, 2085.

21. Kipnis, D. M., and Reiss, E. The effect of cell structure and growth hormone on protein synthesis in striated muscle (abstract). J. clin. Invest. $1960,39,1002$.
22. Allen, D. W., and Jandl, J. H. Kinetics of intracellular iron in rabbit reticulocytes. Blood 1960, 15, 71.

23. Gray, C. H., and Scott, J. J. The effect of haemorrhage on the incorporation of $[\alpha-14 \mathrm{C}]$ glycine into stercobilin. Biochem. J. 1959, 71, 38.

24. Stohlman, F. Observations on the kinetics of red cell proliferation in The Kinetics of Cellular Proliferation, F. Stohlman, Ed. New York, Grune and Stratton, 1959, p. 318.

25. Alpen, E. L., and Cranmore, D. Observations on the regulation of erythropoiesis and on cellular dynamics by $\mathrm{Fe}^{50}$ autoradiography. Ibid., p. 290.

26. Lajtha, L. G., and Suit, H. D. Uptake of radioactive iron $\left({ }^{50} \mathrm{Fe}\right)$ by nucleated red cells in vitro. Brit. J. Haemat. 1955, 1, 55.

27. Suit, H. D., Lajtha, L. G., Oliver, R., and Ellis, F. Studies on the ${ }^{50} \mathrm{Fe}$ uptake by normoblasts and the failure of $\mathrm{X}$-irradiation to affect uptake. Brit. J. Haemat. 1957, 3, 165.

28. Gavosto, F., Maraini, G., and Pileri, A. Radioautographic investigations on DNA and protein metabolism in 2 cases of Di Guglielmo's disease. Blood 1960, 16, 1122.

29. Sondhaus, C. A., and Thorell, B. Microspectrophotometric determination of nonheme iron in maturing erythroblasts and its relationship to the endocellular hemoglobin formation. Blood 1960, 16, 1285.

30. London, I. M. Metabolism of the mammalian erythrocyte. Bull. N. Y. Acad. Med. 1960, 36, 79. 